\title{
PERSPECTIVAS SOCIAIS E POLÍTICAS DA FORMAÇÃO DE NÍVEL MÉDIO: AVANÇOS E ENTRAVES NAS SUAS MODALIDADES
}

\author{
GAUDÊNCIO FRIGOTTO* \\ MARIA CIAVATTA**
}

"O novo é o aprendizado intelectual"

(Acacia Kuenzer) $^{1}$

\begin{abstract}
RESUMO: Tratamos de perspectivas para o ensino médio do ponto de vista das questões mais amplas que as determinam como totalidades sociais. Entendemos que os processos educativos são constituídos e constituintes da sociedade e sinalizamos particularidades da sociabilidade capitalista em países dependentes como os latino-americanos, em particular, o Brasil. A seguir, apresentamos concepções teóricas e ideologias em confronto nas propostas de ensino médio no Brasil e algumas das principais disputas das políticas educacionais em curso. Nas considerações finais, sinalizamos entraves, desafios e perspectivas.
\end{abstract}

Palavras-chave: Ensino médio. Sociabilidade capitalista. Política educacional.

\section{SOCIAL AND POLITICAL PERSPECTIVES OF HIGH SCHOOL: ADVANCES AND OBSTACLES IN THEIR MODALITIES}

ABSTRACT: We treat the perspectives for high school education in terms of broader issues that determine them as social totalities. We understand that the educational processes both constitute the society and are constituted by it. We highlight peculiarities of capitalist sociability in dependent countries such as those in Latin America, particularly Brazil. We then present the theoretical concepts and ideologies that confront in the high school proposals in Brazil and some of the biggest disputes in the current educational policies. Our closing remarks stress the barriers, challenges and perspectives.

Key words: High school. Capitalist sociability. Educational policy.

* $\quad$ Doutor em Ciências Humanas (Educação) e professor no Programa de Pós-Graduação em Políticas Públicas e Formação Humana na Universidade do Estado do Rio de Janeiro (UERJ). E-mail: gfrigotto@globo.com

** Doutora em Ciências Humanas (Educação) e professora titular em Trabalho e Educação, associada ao Programa de Pós-Graduação em Educação da Universidade Federal Fluminense (UfF). E-mail: mciavatta@terra.com.br 


\title{
Perspectives sociales et politiques de l'Éducation de niveau SECONDAIRE: AVANCÉES ET LES OBSTACLES À LEUR MANIÈRE
}

\begin{abstract}
RÉSUMÉ: Nous abordons les perspectives du lycée du point de vue des grandes questions sociales qui les déterminent comment totalités. Nous comprenons que les processus éducatifs constituent la société et sont constitués par cette dernière. Nous signalons les particularités de la sociabilité capitaliste dans les pays dépendants comme ceux d'Amérique Latine, notamment le Brésil. Nous présentons ensuite les conceptions théoriques et idéologies qui s'opposent dans les propositions pour le lycée au Brésil et certains des conflits majeurs dans le cadre des politiques éducatives. Nos remarques de clôture mettent en relief les obstacles, défis et perspectives.
\end{abstract}

Mots-clés: Lycée. Sociabilité capitaliste. Politique d'éducation.

\section{Introdução}

$\mathrm{N}$ ão apenas no Brasil, mas na América Latina, estamos longe de oferecer à maioria das crianças e jovens condições educativas para o aprendizado intelectual, o qual pressupõe denso tempo de leitura, laboratórios, espaços de lazer, arte e cultura. Continuamos presos a uma sociedade de classes, onde, não obstante o discurso em contrário e os avanços ocorridos, o aprendizado intelectual de excelência é uma reserva das elites, algo bem próximo à formação dos jovens nobres dos latifúndios da Colônia e do Império, enviados a Lisboa e Coimbra.

Ao transpor a última década do século xx para o novo século, a educação básica de nível médio se viu a braços com uma geração de adolescentes, jovens ou adultos, onde quase $50 \%$ com mais de 15 anos não têm acesso à mesma e os que têm, em sua maioria, é de forma precária, tanto na sua base material quanto pedagógica. Uma profunda contradição, diante da presença das ciências e da tecnologia na vida cotidiana. Outras contradições são encontradas no mundo do trabalho e nas suas relações com o capital. As condições de desemprego, subemprego, terceirização, trabalho precário, desregulamentado, fazem crescer a pobreza, senão a miséria, nos países não desenvolvidos e induzem ao empobrecimento e aos desequilíbrios sociais nos países ricos.

Neste texto, as perspectivas para o ensino médio são tratadas do ponto de vista das questões mais amplas que as determinam como totalidades sociais. Primeiro, entendendo que os processos educativos são constituídos e constituintes do modo dominante da sociedade, traçamos um panorama da sociabilidade capitalista gerada pelo desenvolvimento desigual e combinado, a que estão sujeitos países de capitalismo dependente ${ }^{2}$ como os latino-americanos e, neste contexto, quais as concepções teóricas e ideologias em confronto e o que baliza as propostas de ensino médio no 
Brasil, atualmente; segundo, trazemos alguns elementos das principais disputas das políticas educacionais para o ensino médio e a educação de jovens e adultos; e, por último, algumas considerações finais em termos dos entraves, de desafios e perspectivas. $^{3}$

\section{As relações entre o projeto societário de desenvolvimento e o nível de ensino médio como educação básica}

Qualquer que seja o objeto de análise no campo das ciências humanas e sociais que se queira tratar no plano da historicidade, vale dizer, no campo das contradições, mediações e determinações que o constituem, implica necessariamente tomá-lo na relação inseparável entre o plano estrutural e o conjuntural. Por outra parte, implica tomar o objeto de análise não como um fator isolado ou soma de fatores, mas através das mediações que o constituem como parte de uma totalidade histórica.

Desse modo, as concepções, as ideologias, teorias e políticas relativas à educação e, no caso em análise, ao ensino médio ganham sentido histórico quando aprendidas no conjunto de relações sociais de produção da existência e dentro de um determinado contexto. ${ }^{4}$

Um olhar, ainda que breve, sobre a herança histórica dos países latino-americanos nos explicita que, mesmo com particularidades, acresce-se ao seu caráter estrutural de sociedades cindidas em classes as marcas, no passado, de longos processos de colonização e escravidão e, no presente, pela conformação de sociedades de capitalismo dependente de desenvolvimento desigual e combinado. Em termos mais amplos, Quijano (2000), em análise sobre a colonialidade do poder na América Latina, sublinha alguns traços marcantes da herança colonizadora e escravocrata, cujas marcas se apresentam nos projetos societários no presente. Historicamente, indica-nos o autor, houve um processo de descolonização, ainda que limitado, mediante um efetivo processo revolucionário em países como México e Bolívia, mas, a partir dos anos de 1980, houve um alinhamento de, praticamente, todos os países com as políticas neoliberais.

Em termos reais, isto significa sociedades em que suas classes dominantes, associadas de forma ativa, mas subordinadas aos grandes centros hegemônicos do capital, abrem espaço à expansão do capital, mormente o capital financeiro, cujo único fim é especular para auferir lucros, independente da produção.

Em duas obras - Para além do capital (2000) e O desafio e o fardo do tempo histórico (2007) -, Mészáros, com base sobretudo em Marx, nos revela os efeitos dessa regressão materializada no fato de que o sistema capital, para manter-se, tem que se 
fundar cada vez mais num processo de produção destrutiva. Destruição de um a um dos direitos conquistados pela classe trabalhadora, aliada a um processo violento de superexploração e precarização do trabalho, e destruição das bases da vida mediante a agressão ao meio ambiente.

O conjunto de ideias pragmáticas, sintetizadas no que ficou conhecido como Consenso de Washington, expressa, no plano político prático, o conteúdo e método desta regressão violenta que se efetivou pelo desmonte do Estado na sua face social e pelo desmanche do patrimônio público por meio das privatizações. Concomitantemente, houve a agressão às organizações dos trabalhadores para enfraquecê-las frente ao capital e deixar caminho aberto à espoliação.

O sucesso desta engenharia social dependia de uma investida no campo das ideias, na busca de criar um consenso conformista nas massas e reforçar a doutrina do livre mercado, da competição e da busca do sucesso individual. No plano mais geral, situa-se a tese de Fukuyama (1992), na qual toma como verdade cabal a visão particular da burguesia, da natureza dos homens, utilitarista, egoísta, empreendedora e do livre mercado como ideal de relações humanas.

Neste novo contexto do sistema capital, a maioria das sociedades latinoamericanas, que mal saía de ferrenhas ditaduras e retomava ativamente lutas por mudanças estruturais, foi atordoada por sucessivos ajustes impostos pelos organismos internacionais, de tal sorte que o capital pudesse transitar livremente para auferir lucros sem limites. Assim, a doutrina neoliberal - com variantes de processos de resistência dos movimentos sociais e sindicatos que defendem, numa ótica de classe, os trabalhadores - encontrou o consentimento ativo das burguesias locais.

A América Latina tornou-se, a começar pelo Chile, o laboratório prático do neoliberalismo num duplo movimento: pelo desmonte do Estado, venda do patrimônio público mediante intenso processo de privatização e pelo processo de desregulamentação e flexibilização do trabalho. A grande maioria dos países latino-americanos transita, desse modo, das ditaduras civis-militares à ditadura do mercado. Enquanto as ditaduras, expressão de falta de hegemonia, criaram resistências ativas, o pensamento neoliberal, com apoio massivo dos grandes meios de comunicação, foi criando um consenso de que não há mais alternativa ao capitalismo. Constrói-se, por essa via, o que Oliveira (1999) denomina de totalitarismo neoliberal para designar a construção de uma sociabilidade de apartação e uma subjetividade antipública. Resulta daí uma profunda vingança do capital contra os trabalhadores e consequente regressão econômico-social, política, educacional e cultural.

Para o caso brasileiro, Oliveira (2007) nos traça as mediações básicas destes percursos, caracterizando o período de 1930 a 1990 como era das invenções, para 
designar uma intensa mobilização da sociedade brasileira no campo do embate político em todas as áreas. Nem mesmo a ditadura Vargas, na década de 1930, e os 20 anos de ditadura civil-militar iniciada em 1964 anularam a disputa do projeto societário. É a partir do final da década de 1980, com o governo Collor de Mello e, de modo decisivo, nos oito anos do governo Fernando Henrique Cardoso, na década de 1990, com ostensivo apoio da burguesia brasileira e seus aparelhos de hegemonia, que se efetiva o desmanche da nação e uma era da indeterminação da política. Esta se expressa especialmente no fato de que as organizações da classe trabalhadora, por diferentes mecanismos, já não contam com a classe dominante, mediante uma ação política que explicite o conflito e a disputa de interesses. O que passa a dominar é a autonomização do mercado (Oliveira, 2007, p. 36).

Mais uma vez, na história da educação brasileira, com a eleição do Presidente Lula da Silva, em outubro de 2002, e pelo que abordaremos adiante, não há alterações substantivas no governo Dilma Rousseff. As expectativas de mudanças estruturais na sociedade e na educação, pautadas nos direitos inscritos na Constituição Federal de 1988, não se realizaram. Apesar da produção de conhecimentos sobre contradições, desafios e possibilidades da educação, como um projeto universalizado para toda a população, que esperávamos ser apropriado pela política pública do Estado brasileiro, o que tem se revelado é um percurso controvertido entre as lutas da sociedade, as propostas de governo e as ações, entraves e omissões no exercício do poder. ${ }^{5}$

O conceito de capitalismo dependente, elaborado especialmente por Marini (2000) e Fernandes (1973), que combina elevada concentração de riqueza e capital e de desigualdade, define o caráter de nossa especificidade histórica na sua raiz mais profunda. Trata-se de um conceito que nos permite explicitar o caráter ideológico da "teoria" da modernização, ao situar o núcleo explicativo na relação e no conflito de classes no sistema capitalista. O conceito de capitalismo dependente não se confunde com dualidade e, também, não é um confronto entre nações, mas é aliança e associação subordinadas da fração brasileira da burguesia às burguesias dos centros hegemônicos do sistema capital, na consecução de seus interesses.

Consolidam-se, dessa forma, relações de poder e de classe que foram sendo construídas no Brasil ao longo deste século e que, como analisa Oliveira (2003a), permitiram apenas parcial e precariamente a vigência do modo de regulação fordista, tanto no plano tecnológico quanto no plano social. O mesmo ocorre no presente, na atual mudança científico-técnica de natureza digital-molecular, que imprime uma grande velocidade à competição e à obsolescência dos conhecimentos. Isto, destaca Oliveira (op. cit.), torna nossa tradição de cópia ainda mais inútil e colabora para consolidar relações sociais de uma sociedade desigualitária e sem remissão, que produz a miséria e se alimenta dela. 


\section{A historicidade das políticas educacionais para o ensino médio: entraves, avanços e desafios}

As indicações anteriores sinalizam a natureza das disputas de concepções e políticas no campo educacional, mormente a partir das ditaduras na América Latina. ${ }^{6}$ Foi ao longo da ditadura, no Brasil, que se introduziu e se assimilou, de forma submissa, a ideologia do capital humano, formulada por Schultz (1973), e sob sua égide se efetivaram as reformas educacionais da pré-escola à pós-graduação. Tal noção, embora reduza a educação de direito social e subjetivo a um fetiche mercantil, ainda tem como referência a integração na sociedade e a ideia de pleno emprego.

Foi no embate com esse ideário que, ao longo da década de 1980, no processo constituinte e, em seguida, no debate da nova Lei de Diretrizes e Bases da Educação Nacional (LDBEN), mais de trinta organizações científicas e sindicais ligadas aos interesses mais amplos da sociedade e da classe trabalhadora constituíram o Fórum Nacional em Defesa da Escola Pública gratuita, laica, universal e unitária. Foi também neste período que, no debate do ensino médio, em suas diferentes modalidades, a concepção da educação politécnica se contrapôs às visões do tecnicismo, do adestramento e da polivalência.

O termo "politecnia" foi apropriado no sentido da educação socialista do início do século $\mathrm{xx}$, como "domínio dos fundamentos científicos das diferentes técnicas que caracterizam o processo de trabalho produtivo moderno" (Saviani, 1989, p. 17), reafirmado por Saviani (2003) 7 e por outros pesquisadores, a exemplo de Kuenzer (1988), Machado (1989), Frigotto (1988) e Rodrigues (1998).

Contudo, é na década de 1990, sob a base da mundialização do capital, das reformas que consubstanciam o desmanche do Estado na garantia de direitos coletivos e universais e do avassalador processo de privatizações, que a ideologia do capital humano se redefine, mediante as noções de sociedade do conhecimento, qualidade total, pedagogia das competências, empregabilidade e empreendedorismo.

Trata-se de noções que hipertrofiam a dimensão individualista e da competição e induzem à formação aligeirada de jovens e adultos trabalhadores em cursos pragmáticos, tecnicistas e fragmentados ou a treinamentos breves de preparação para o trabalho simples, ${ }^{8}$ forma dominante a que somos condenados na divisão internacional do trabalho. E, de acordo com as necessidades do mercado, prepara-se uma minoria para o trabalho complexo.

A eleição do operário e líder sindical Luiz Inácio Lula da Silva, em 2002, à Presidência da República, como sinaliza Oliveira (2003a, p. 3), pela base social que dispunha poderia 
(...) significar uma espécie de quarta refundação da história nacional, isto é, um marco de não retorno a partir do qual se impõem novos desdobramentos (...). É tarefa das classes dominadas civilizar a dominação, o que as elites brasileiras foram incapazes de fazer. $\mathrm{O}$ que se exige do novo governo é de uma radicalidade que está muito além de simplesmente fazer um governo desenvolvimentista.

Uma ampla produção crítica, a começar pela do próprio Oliveira, permite-nos sustentar que, por diferentes razões e determinações, não ocorreu o caminho do não retorno e a opção esteve centrada na realização de um governo desenvolvimentista e, portanto, de natureza modernizante. A radicalidade a que o autor se refere, no contexto das forças em jogo, seria uma opção clara de efetivação de medidas políticas profundas, capazes de viabilizar a repartição da riqueza e suas consequências em termos de reformas de base e pautando um projeto de desenvolvimento endógeno de efetiva sustentabilidade e para uma nação autônoma e soberana. ${ }^{9}$ Por isso, no plano estrutural, não há mudanças no projeto societário entre o governo Fernando Henrique Cardoso e os governos subsequentes, Luís Inácio Lula da Silva e Dilma Rousseff. Isto se reflete, tendencialmente, em ajustar a educação e o ensino profissional técnico de nível médio às recomendações dos organismos internacionais e às demandas do neodesenvolvimentismo, cuja lógica se sustenta na modernização que tem como marca histórica a expansão do capital. ${ }^{10}$

Conservam-se, assim, uma estrutura e as relações de classes sociais ${ }^{11}$ que reiteram a desigualdade no acesso aos bens e aos serviços produzidos pelo conjunto da sociedade, mantém-se um tecido social com profundas marcas da colonização e do escravismo e um consequente preconceito e descriminação do trabalho manual e técnico.

Esta estrutura opaca e violenta da classe detentora do capital, no Brasil, radicaliza a dualidade estrutural na educação, especialmente a partir da década de 1940, quando a educação nacional é organizada através das Leis Orgânicas, segmentando a educação de acordo com os setores produtivos e as profissões, separando os que deveriam ter o ensino secundário e a formação propedêutica para o ingresso na universidade e os que deveriam ter formação profissional para os setores produtivos.

Os governos militares (1964-1984) sinalizam a ruptura com as oligarquias rurais - processo iniciado ao longo dos anos de 1920 e 1930 - e a implantação autoritária da ordem social burguesa e da ordem econômica industrial capitalista. No período, há a entrada decisiva do capital internacional, apesar da declarada política nacionalista, e implantam-se um modelo concentrador de renda, um processo extenso de modernização e desenvolvimento econômico e novos padrões de consumo para uma camada restrita da população.

Com a ajuda internacional, faz-se a Reforma Universitária e a Reforma do Ensino de primeiro e segundo graus (ensino primário ou fundamental e ensino médio), 
que revertem a unidade da LDBEN de 1961, através de leis próprias aos diferentes níveis de ensino. A lei respondia a duas exigências do modelo político-econômico imposto pela ditadura: preparar abundante mão de obra para a produção e desviar, para a opção técnica e profissional, a massa de estudantes que, impulsionados pela oferta educativa dos anos de 1950 e 1960, buscavam o ensino superior.

A permanência de entraves e alguns avanços podem ser identificados a partir da LDben (Lei n. 9.394, de 20 de dezembro de 1997), que reunifica, em uma lei maior, os níveis e modalidades da educação no país. Mas a universalidade da lei não impede que muitos decretos sejam exarados e numerosos programas de governo sejam criados. Continuando as políticas do governo neoliberal de Fernando Henrique Cardoso, mas criando alternativas em resposta aos setores da sociedade civil organizada, gerou-se um quadro ambíguo de políticas educacionais, em grande parte orientadas pelos organismos internacionais, outras resultantes de pressões sociais dos setores mais atuantes em defesa da elevação de escolaridade e da educação profissional dos trabalhadores; outras, particularmente, a partir dos setores empresariais e do Sistema S, demandando a formação estrita de mão de obra. Nas dimensões deste texto, vamos abordar algumas dessas iniciativas.

\section{Os Decretos n. 2.208, 5.154/04 e n. 5.840/06, PROEJA}

Os Decretos foram exarados em 17 de abril de 1997, pelo governo FHC, e em 23 de julho de 2004 e 13 de julho de 2006, pelo governo Lula. O primeiro Decreto teve um efeito perverso de consolidação da fragmentação entre a educação geral e a formação profissional. Pela razão aparente de regulamentar artigos da Lei n. 9.394/97, o Decreto n. 2.208/97, revogado pelo de n. 5.154/04, contrariou os termos da Lei, e é uma síntese emblemática do ideário da educação para o mercado, separando o ensino médio da educação profissional.

O Decreto n. 5.154/04 manteve parte das determinações do anterior, como as formas de articulação entre o ensino médio e a educação profissional, a concomitância e os cursos subsequentes. Todavia, introduziu a alternativa de articulação do ensino médio com a educação profissional e técnica, como formação integrada. O Decreto n. 5.154 foi incorporado à LDB pela Lei n. 11.741, de 16 de julho de 2008. O tema foi objeto de polêmica (entre outros, ver Frigotto, Ciavatta \& Ramos, 2005, e Rodrigues, 2006), ao reintroduzir o ensino médio integrado à educação profissional, propondo articular conhecimento, cultura e trabalho.

Guardadas as diferenças históricas, sua origem remota está na educação socialista, politécnica ou tecnológica (Marx, 1980), que pretendia ser omnilateral no sentido de formar o ser humano na sua integralidade física, mental, cultural, política e científico-tecnológica. A origem recente da ideia de integração entre a formação 
geral e a educação profissional está nas lutas pela democracia e em defesa da escola pública nos anos de 1980, que buscavam assegurar uma formação básica que superasse a dualidade entre cultura geral e cultura técnica, assumindo o conceito de politecnia.

Estas questões incluem a orientação de uma modalidade de ensino prevista pela LDB, a educação de jovens e adultos, regulamentada pelo Decreto n. 5.840, de 13 de julho de 2006, que instituiu o Programa Nacional de Integração da Educação Profissional com a Educação Básica na Modalidade de Educação de Jovens e Adultos (PRoeja). Sua implantação na rede federal de ensino também se reveste de controvérsias. Mas é uma conquista em processo, dos trabalhadores e fruto de intensa mobilização de educadores ligados à educação popular e à educação de jovens e adultos, em favor de políticas que rompessem com o formato tradicional dos cursos supletivos e integrassem essa modalidade de educação no sistema regular de ensino fundamental e médio. ${ }^{12}$

\section{Diretrizes Curriculares Nacionais}

O Parecer CNe/сев n. 16/99, de 5 de outubro de 1999, trata das Diretrizes Curriculares Nacionais (DCN) para a Educação Profissional de Nível Técnico e a Resolução CNE/CEB n. 04/99, de 5 de outubro de 1999, institui as mesmas Diretrizes para orientar a implantação do Decreto n. 2.208/97.

Seus termos gerais são o preâmbulo de uma polêmica sobre a introdução da noção de competências gerais como adaptação às exigências do mercado que se arrastaria por anos, acrescida da separação entre o ensino médio e a educação profissional:

\footnotetext{
A separação entre educação profissional e ensino médio, bem como a rearticulação curricular recomendada pela LDB permitirão resolver as distorções apontadas. Em primeiro lugar, eliminando uma pseudointegração que nem preparava para a continuidade de estudos, nem para o mercado de trabalho. Em segundo lugar, focando na educação profissional a vocação e missão das escolas técnicas e instituições especializadas, articuladamente com escolas de nível médio responsáveis por ministrar a formação geral, antes a cargo da então "dupla" missão das boas escolas técnicas. (Brasil, 2001, p. 114-115)
}

Com a exaração do Decreto n. 5.154/04, o mesmo relator, prof. Francisco Aparecido Cordão, atualizou as DCN dentro das orientações técnicas do Parecer anterior, através do Parecer CNE/СЕв n. 39/2004, de 8 de dezembro de 2004, abstraindo o significado da alternativa "formação integrada" aberta pelo novo Decreto.

No início dos anos de 2010, o relator do CNE/CEB reiterou, pela terceira vez, os fundamentos originais das DCN para EPT de 1999. Não obstante algumas mudanças de expressão, justifica-os "à luz das alterações trazidas pela Lei n. 11.741/2008" 
(Brasil, 2010, p. 3), que reeditou os artigos modificados na LDB pelo Decreto n. 2.208/97 e incorporou o de n. 5.154/04.

Um grupo de professores e gestores das instituições federais de educação profissional e tecnológica, em seminário realizado em Brasília, nos dias 5 e 6 maio de 2010, "ciente da necessidade de ampliação do debate e da formulação de uma sólida contribuição em termos de explicitação e aprofundamento das concepções que devem nortear as ofertas de educação profissional e tecnológica", passou ao estudo e discussão, com o apoio da SETEC, de um documento alternativo à nova versão das DCN do CNE/CEB ${ }^{13}$ (Diretrizes, 2010).

Do processo de discussão emergiu a cooperação com a Secretaria de Educação Básica, para a elaboração das DCN para o ensino médio (idem, ibid.). Considerando a especificidade do ensino médio, o novo documento sobre as DCN tem por base a concepção de educação como formação humana, que presidiu a elaboração das Diretrizes para EPT. O Parecer CNE/CEB n. 05/2011 e o Projeto de Resolução para as DCN do ensino médio foram aprovados pelo cNE em 5 de maio de 2011 (Brasil, 2011). O Parecer reitera os pressupostos comuns com o documento alternativo do grupo de trabalho (GT) para as DCN da EPT: as dimensões da formação humana no trabalho, na ciência e na cultura; o trabalho como princípio educativo; a pesquisa como princípio pedagógico. Coloca os desafios para sua implementação e trata do projeto político-pedagógico, da organização curricular e do compromisso de sucesso com os estudantes.

O desfecho político do texto final das DCN para EPT ainda não é previsível, diante da disputa posta com a ideologia da funcionalidade da educação profissional para o mercado sustentada pelo empresariado, o que supõe orientações político-pedagógicas de maior clareza, por parte do MEC, quanto ao lugar do ensino médio e da educação profissional na formação dos jovens e dos trabalhadores. Temos claro que não é possível uma educação profissional de qualidade sem uma educação básica de qualidade, universalizada, pública, gratuita, obrigatória, assumida pelo Estado, como um projeto de educação para toda a população.

Com base na Carta de $\mathrm{Natal}_{,}{ }^{14}$ convidados pela SETEC, participantes do primeiro GT e de outras instituições elaboraram uma carta, assinada por 35 representantes presentes, dirigida ao presidente da СЕв/CNE, prof. Francisco A. Cordão, onde estão expostas as questões básicas de divergência com o documento das DCN para EPT do CNE/CEB:

(a) diverge dos pressupostos e objetivos das Diretrizes Curriculares Nacionais para o Ensino Médio, aprovadas recentemente pelo CNE;

(b) "fortalece a separação entre o ensino médio e a educação profissional estabelecida pelo Decreto n. 2.208/97 já revogado"; 
(c) "não incorpora os pressupostos filosóficos e educacionais que sustentam a formação integrada prevista pelo Decreto n. 5.154/04";

(d) "enfatiza a centralidade da educação profissional na dimensão econômica, tomando o mercado como instrumento regulador da sociabilidade humana";

(e) "baseia-se no currículo centrado na pedagogia das competências";

(f) "aponta para uma organização curricular fragmentada, caracterizada pelas saídas intermediárias, implicando a precarização da formação" (Oliveira, 2011, p. 1).

O grupo reitera o documento elaborado no âmbito do GT constituído pela SETEC, em 2010, que expressa "os conceitos e concepções que vêm sendo assumidos pelo MEC, desde 2003, em relação à educação profissional":

(i) centralidade no ser humano e suas relações sociais, sem ignorar as exigências da produção econômica, como campo de onde os sujeitos sociais retiram os meios de vida;

(ii) formação que aponta para a superação da dualidade histórica entre formação básica e formação profissional;

(iii) currículo centrado na concepção de formação humana integral, tendo como eixo estruturante a integração entre trabalho, ciência, tecnologia e cultura, baseando-se no trabalho como princípio educativo e, entre outros, nos seguintes fundamentos pedagógicos: construção coletiva do projeto políticopedagógico; pesquisa como princípio pedagógico; articulação com o desenvolvimento socioeconômico e a educação ambiental (idem, ibid., p. 2).

\section{A universalização de educação básica}

A universalização de educação básica é uma necessidade incontornável no Brasil, mas está imersa em ambiguidades. A educação básica (pré-escolar, fundamental e média), dos 4 aos 17 anos, tornou-se direito subjetivo pela Emenda Constitucional n. 59, de 11 de novembro de 2009, e pela Lei n. 12.061, de 27 de outubro de 2009.

Não obstante os avanços na lei e os desafios da prática, prevalece o sentido do falso "dilema" do ensino médio no Brasil que, diante da alternativa de uma educação de qualidade pública, obrigatória e gratuita para toda a população na idade prevista, oferece a meia educação através da educação profissional como preparação imediata para o mercado de trabalho. A lei aprovada tem importância porque torna a educação básica dos 4 aos 17 anos um direito subjetivo. 
A Emenda Constitucional n. 59 trata dos recursos destinados à manutenção e desenvolvimento do ensino (artigo 12 da Constituição Federal e incisos I e II do artigo 208) e explicita a questão da obrigatoriedade: "Educação básica obrigatória e gratuita dos 4 (quatro) aos 17 (dezessete) anos e ampliar a abrangência dos programas suplementares para todas as etapas da educação básica" (artigo 208, inciso I).

Contudo, o resultado frustra o direito: substituiu-se "a progressiva extensão da obrigatoriedade e gratuidade ao ensino médio" (artigo $4^{\circ}$, inciso II da Lei n. 9.394/97) por uma breve expressão "universalização do ensino médio gratuito" (artigo $4^{\circ}$, inciso II da Lei n. 12.061, de 27 de outubro de 2009). O detalhe significativo é a ausência do termo "obrigatoriedade" que, ipso facto, isenta o Estado do compromisso com a universalização.

\section{O Plano Nacional de Educação}

O Plano Nacional da Educação (2001-2010) mostrou o que se renova neste momento, no atual PNE (2011-2020): um percurso controvertido, onde permanece a disputa por um projeto societário e de educação que eleve toda população brasileira a outro patamar, de conhecimento e de participação democrática na riqueza social. Recente artigo publicado na Folha de S. Paulo denuncia incongruências de nossas políticas educacionais, mas mostra um pensamento conservador, ativo, que tira a máscara dos bastidores do poder e declara: "PNE é lista de Papai Noel" (Castro, Oliveira \& Schwartzman, 2011).

Para os tradicionais articulistas, a proposta a ser aprovada pelo Congresso Nacional, até novembro próximo, "poderá sofrer emendas, mas dificilmente será alterada na sua essência. Os dois planos anteriores oscilaram entre utopias e inconsequências. Não se espera nada diferente agora". Os encontros da sociedade civil (sindicatos, associações, ongs) resultaram "numa enorme lista de Papai Noel (...) o Ministério não tem escolas de nível básico, tampouco instrumentos para convencer prefeitos a gastar o prescrito ou operar de modo diferente. O mesmo acontece com os Estados" (idem, ibid., p. A3).

Algumas afirmações evidenciam os limites da realidade da educação brasileira e podem ser lidas como um alerta, mas outras, na série de "caminhos" indicados, revelam as orientações internacionais para a educação nos países de capitalismo dependente: "mais dinheiro não implica melhores resultados" (embora seja correto pensar que "são necessárias políticas consistentes e persistência na implementação"); ênfase nos resultados, parcerias público-privadas, alinhar materiais pedagógicos e sistemas de avaliação; avaliação e certificação dos professores (ibid.). 
Uma análise política mais abrangente e menos operacional do PNE, agora subsumido ao Plano de Desenvolvimento da Educação (PDE) que o secundariza, mereceu de Saviani $(2007$, p. 3) a seguinte análise:

\begin{abstract}
Fica-se com a impressão de que estamos diante, mais uma vez, dos famosos mecanismos protelatórios. Nós chegamos ao final do século xx sem resolver um problema que os principais países, inclusive nossos vizinhos Argentina e Uruguai, resolveram na virada do século xIX para o xx: a universalização do ensino fundamental com a consequente erradicação do analfabetismo.
\end{abstract}

E referindo-se às políticas, conclui: “(...) do ponto de vista da pedagogia histórico-crítica, o questionamento ao PDE dirige-se à própria lógica que o embasa. Com efeito, essa lógica poderia ser traduzida como uma 'pedagogia de resultados'"' (idem, ibid.).

O III Seminário de Educação Brasileira, realizado de 28/2 a 1\%/03/2011, pelo Centro de Estudos Educação e Sociedade (CEDEs), reuniu pesquisadores de todo o país para analisar o novo Plano Nacional de Educação (2011-2020). Em relação às Metas 3, 4 e 10, que tratam do ensino médio, destacamos alguns pontos: elas reiteram as demandas de universalização de educação básica como responsabilidade do Estado, mas consideram que o limite estabelecido dos 4 aos 17 anos nega o direito à educação aos que estão fora dessa faixa etária; reivindicam a construção de uma política curricular guiada pelo princípio da integração entre trabalho, ciência e cultura; propõem excluir o Exame Nacional de Ensino Médio (ENEM) como critério de acesso ao ensino superior, pelo seu poder de modelação do ensino médio (Moraes, 2011).

Outros instrumentos legais estão em processo de implantação no país com vistas à expansão da educação como um todo, do ensino médio e da educação profissional. Sobre eles, ainda não temos pesquisa, mas apenas as informações oficiais divulgadas pelo MEC, como o Programa Brasil Profissionalizado (Decreto n. 6.094, de 24 de abril de 2007, de expansão da rede de educação profissional e tecnológicas nos estados); o pronatec, lançado pela Presidência da República em 28 de abril de 2011 e que, à semelhança do PROUNI, tem o objetivo de fornecer bolsas para educação profissional, no setor privado, e caminha na direção oposta à universalização do ensino médio público, gratuito, obrigatório e de qualidade. ${ }^{15}$

\title{
A título de considerações finais
}

Um artigo com características de ensaio, embora fundamentado em análises provenientes de trabalhos de pesquisa dos seus autores e de outros interlocutores, não tem a mesma natureza conclusiva do texto final de uma investigação. Isto, 
todavia, não diminui sua pertinência e validade como apreensão crítica do tema em debate.

O ponto central da análise foi a busca das razões por que, em mais de meio século (tendo como marco a LDBEN, Lei n. 4.024/61), não se alterou substancialmente a oferta de ensino médio público, gratuito, de qualidade. Não se constituiria este um nível estratégico da formação básica para o trabalho e a atuação política, social e cultural dos jovens? E não seria também fundamental para o desenvolvimento científico e tecnológico do país, de modo a ampliar os graus de autonomia e soberania nacional? Não por acaso, estes são termos em desuso.

Dois aspectos tornam esta questão ainda mais intrigante e aparentemente um enigma. O primeiro é que, de tempos em tempos, em momentos de expansão da economia, a imprensa, lideranças empresariais e intelectuais a elas vinculados explicitam uma metáfora que se reitera: o apagão educacional. Isso para apontar a falta de mão de obra qualificada para preencher os postos de trabalho de que necessitam os diferentes setores da economia. Esta metáfora reapareceu de forma insistente a partir de 2007, com o "Plano de Aceleração do Crescimento" (PAC), cuja meta era de crescimento do Produto Interno Bruto (РІв) de aproximadamente $5 \%$. O senador Cristovão Buarque, ex-ministro da Educação, sugeriu uma Comissão Parlamentar de Inquérito (CPI) do "apagão". A própria metáfora impactante de "apagão educacional" dá a entender algo conjuntural e momentâneo e que pode ser corrigido rapidamente, talvez por um programa emergencial.

O segundo aspecto do aparente enigma situa-se no fato de que este quadro não se alterou substantivamente no governo do ex-operário Luiz Inácio Lula da Silva e em sua continuidade atual pela presidenta Dilma Rousseff, cuja base social que os elegeu, como sublinhamos no primeiro item pela análise de Francisco de Oliveira, poderia instaurar um marco de não retorno em nossa estrutura de relações sociais.

O enigma do "apagão educacional" no ensino médio pode ser decifrado ao buscarmos, nas análises do pensamento social crítico, as determinações e mediações que demonstram que a classe dominante brasileira foi definindo, ao longo do século $\mathrm{xx}$, um projeto societário de capitalismo dependente, associando-se de forma subordinada aos centros hegemônicos do grande capital e dos organismos internacionais, que representam seus interesses.

Essa definição deu-se, sobretudo, ao longo da década de 1990, com o desmonte do Estado brasileiro e o desmanche do patrimônio público por privatizações criminosas. As reformas educativas da referida década, seguindo o ideário dos organismos internacionais, foi coerente com esta opção. Para este tipo de opção não se coloca como necessidade a universalização do ensino médio. Os que proclamam o 
“apagão educacional", por sua posição de classe, não percebem que o mesmo é cria ou produto de suas decisões e políticas.

A continuidade dos entraves nas políticas do ensino médio e no plano mais amplo da educação em todas as esferas, ao longo do governo Lula da Silva e no presente, situa-se no fato de que a opção de projeto societário não foi pelo marco do não retorno, o qual implicava mudanças estruturais. A opção foi por um projeto desenvolvimentista de caráter modernizador, mantendo uma política econômica ditada pelos organismos internacionais vinculados à expansão do capital.

O diferencial hoje, considerando a década de 1990, situa-se na ênfase ao desenvolvimento e na maior abrangência e organicidade das políticas de alívio à pobreza; também, pela opção de programas de atendimento a demandas reprimidas no campo educacional, especialmente na expansão do ensino médio técnico e ensino superior. Mas, nestes dois casos, isso ocorreu deslocando-se recursos públicos para os setores privados (a exemplo do PROUNi e do PRONATEC), e com base em decisões imediatistas, sem a necessária adequação dos quadros docentes para a expansão prevista (REUNI).

As consequências desta opção, como mostra Oliveira (op. cit.) em reiteradas análises, é de que, em vez de socializar a política, esta foi sendo anulada, esfacelando-se a base social organizada. No plano educacional, este esfacelamento se manifesta pela fragmentação das lutas e perda de um horizonte mínimo de unidade, diferente do que caracterizou as disputas, ao longo da Constituinte na década de 1980, das forças sociais reunidas no Fórum Nacional em Defesa da Educação Pública.

O que fica evidente na breve análise que procedemos no segundo item é que, de forma crescente, as políticas do ensino médio, em todas as suas modalidades e nas diretrizes que orientam suas perspectivas pedagógicas, vêm sendo pautadas pela dominância do pensamento empresarial. Paradoxalmente, o ideário educacional da década de 1990 não só continua, mas se aprofunda na perspectiva do produtivismo e na orientação pragmática e fragmentária das demandas do mercado. Isto fica patente no fato de que o Plano de Desenvolvimento da Educação, pautado, sobretudo, no pensamento empresarial e nas parcerias entre público e privado, está comandando as medidas educacionais em curso e subordinando, a tal perspectiva, o Plano Nacional de Educação. Esvai-se, assim, a perspectiva do ensino médio como educação básica universalizada e, portanto, direito social e subjetivo de todos os jovens.

O que apontamos com a perspectiva de renascer das cinzas, na correlação de forças dos embates políticos pela orientação do ensino médio, é a proposta do ensino médio integrado e integral, que busca articular conhecimento, trabalho e cultura. Pela particularidade de que mais de um século nos separa de sua concepção, não é, exatamente, o mesmo que a educação politécnica ou tecnológica, mas é, certamente, 
uma travessia a que a realidade rebelde de nossa história nos condiciona. O que está em curso não é uma fatalidade. É uma construção de forças sociais em luta e, por isso, como nos ensina Fernandes (1977, p. 5), a história não se fecha para sempre: "A história nunca se fecha por si mesma e nunca se fecha para sempre. São os homens, em grupos e confrontando-se como classes em conflito, que 'fecham' ou 'abrem' os circuitos da história".

\section{Notas}

1. Palestra proferida no Centro Federal de Educação Tecnológica do Rio de Janeiro, em 6 de outubro de 2005.

2. Sobre países de capitalismo dependente, ver, entre outros, Marini (2000).

3. Algumas análises, expostas neste artigo, foram desenvolvidas individualmente ou em coautoria sobre as reformas do ensino médio técnico e profissional em curso no Brasil (ver Frigotto \& Ciavatta, 2003; Ciavatta, 2005a; Ciavatta, 2005b; Frigotto, Ciavatta \& Ramos, 2005).

4. É importante sublinhar aqui a plena validade e atualidade da síntese conclusiva a que chegou Marx da análise do processo histórico: “O modo de produção da vida material condiciona o desenvolvimento da vida social, política e intelectual em geral. Não é a consciência dos homens que determina o seu ser; é seu ser social que, inversamente, determina a sua consciência" (Marx, 1983, p. 24).

5. Estas considerações apóiam-se em Frigotto, Ciavatta e Ramos (2005a; 2005b).

6. Não há espaço nas dimensões deste artigo para nos determos sobre as mudanças educacionais nos diferentes países latino-americanos. Para uma análise das reformas ocorridas na educação em geral e no nível médio técnico, nas últimas décadas, ver Cunha (2000) e Gajardo e Puryear (2003).

7. Esta reafirmação resulta de um diálogo com Paolo Nosella que, com base nas análises de Mário Manacorda, polemiza a abordagem de Saviani e dos autores já citados, defendendo a tese de que somente a "expressão 'tecnologia' evidencia o germe do futuro, enquanto 'politecnia' reflete a tradição cultural anterior a Marx, que o socialismo real de Lenin impôs à terminologia pedagógica de sua política educacional" (Nosella, 2007, p. 145).

8. "Trabalho humano mede-se pelo dispêndio da força de trabalho simples, a qual, em média, todo homem comum, sem educação especial possui em seu organismo. O trabalho simples médio muda de caráter com os países e estágios da civilização, mas é dado numa determinada sociedade. Trabalho complexo ou qualificado vale como trabalho simples potenciado ou, antes, multiplicado, dado que uma determinada quantidade de trabalho qualificado é igual a uma quantidade maior de trabalho simples" (Marx, 1980, p. 51; grifos do autor).

9. Para um detalhamento da contribuição do pensamento social crítico brasileiro que aponta este caminho e o do balanço da educação nos oito anos de governo Lula da Silva, ver Frigotto (2011).

10. Para uma análise crítica do neodesenvolvimentismo, ver Castelo (2010).

11. "Classes sociais" é um conceito banido de circulação acadêmica, sob a inspiração da ideologia neoliberal e da primazia do mercado. No Brasil, há evidência ao contrário. O empobrecimento generalizado das classes médias e populares, ao lado do enriquecimento financeiro e bancário das elites, mostra a pertinência do conceito (cf. Marx \& Engels, 1979).

12. Para análises mais detalhadas sobre o significado do PROEJA, entre outros, ver Rummert (2008) e Ciavatta e Rummert (2010).

13. Esse grupo ampliado contou com representantes de entidades e instituições públicas do país (ANPEd, CONIF, CONSED, EPSJV-FIOCRUZ, FNCEE, IFES, IFRN, IFSC, MTE, SEE-BA, SEE-MT, SECT-SC, UEL, UERJ, UFES, UFF, UFPR, UFPA, USP, UTPR), movimentos sociais (CUT, MST, SINASEFE), secretarias do MEC (SEB, SECAD, SEED, 
SEESP, SETEC) e concluiu o documento em dezembro de 2010, quando ele foi encaminhado ao CNE// Сев pelo MEC/SETEC (Diretrizes, 2010).

14. Aprovada no Colóquio "A produção do conhecimento em educação profissional", realizado no IFRN, em Natal, nos dias 19 e 20 de maio de 2011. A Carta, assinada pela ANPEd e por outras associações científicas, está sendo objeto de encaminhamento ao ministro da Educação.

15. Cabe também mencionar outras iniciativas de interesse de empresários, organizações não governamentais e setores influentes da sociedade, que merecem entrevistas e artigos na grande imprensa, como o Plano de Metas Compromisso Todos pela Educação (Decreto n. 6.094, de 24 de abril de 2007).

\section{Referências}

BELL, D. O advento da sociedade pós-industrial. Rio de Janeiro: Cultrix, 1973.

BRASIL. Ministério da Educação. Conselho Nacional de Educação. Câmara de Educação Básica. Parecer CNE/CEB n. 16/99, de 5 de outubro de 1999. Institui as Diretrizes Curriculares Nacionais para a Educação Profissional de Nível Técnico pela Resolução CNE/CEB n. 04/99, de 5 de outubro de 1999.

BRASIL. Ministério da Educação. Conselho Nacional de Educação. Câmara de Educação Básica. Atualização das Diretrizes Curriculares Nacionais para Educação Profissional Técnica de Nível Médio; versão para debates na Audiência Pública Nacional. Brasília, DF, 2010.

BRASIL. Ministério da Educação. Conselho Nacional de Educação. Câmara de Educação Básica. Parecer cne/CEb n. 5, de 5 de maio de 2011. Diretrizes Curriculares Nacionais para o Ensino Médio. Brasília, DF, 2011.

CASTELO, R. (Org.). Encruzilhadas da América Latina no século xxı. Rio de Janeiro: Pão e Rosas, 2010.

CASTRO, C.M.; OLIVEIRA, J.B.A.; SCHWARTZMAN, S. pNe é lista de Papai Noel. Folha de S. Paulo, São Paulo, Opinião, p. A3, 16 jun. 2011.

CIAVATTA, M. A formação integrada: a escola e o trabalho como lugares de memória e de identidade. In: Frigotto, G.; Ciavatta, M.; Ramos, M. (Org.). Ensino médio integrado: concepção e contradições. São Paulo: Cortez, 2005. p. 83-105.

CIAVATTA, M. Perspectivas de educação básica de nível médio: presente e passado no caso brasileiro. Trabalho apresentado no Colóquio Tendencias y Experiencias de Reforma del Bachilerato, México, DF, UNAM, 17 a 19 ene. 2005a. (mimeo.).

CIAVATTA, M.; RUMMERT, S.M. As implicações políticas e pedagógicas do currículo na educação de jovens e adultos integrada à educação profissional. Educação $\mathcal{E}$ Sociedade, Campinas, v. 31, n. 111, p. 461-480, abr./jun. 2010. 
CUNHA, L.A. Ensino médio e ensino técnico na América Latina: Brasil, Argentina e Chile. Cadernos de Pesquisa, São Paulo, n. 111, p. 47-70, dez. 2000.

DIRETRIZES Curriculares Nacionais para a Educação Profissional Técnica de Nível Médio; texto para discussão; documento elaborado por Grupo de Trabalho instituído pela SETEC/MEC. Brasília, DF: SETEC/MEC, 2010.

FERNANDES, F. Capitalismo dependente e classes sociais na América Latina. Rio de Janeiro: Zahar, 1973.

FERNANDES, F. Os circuitos da história. São Paulo: HUCITEc, 1977.

FRIGOTTO, G. A produtividade da escola improdutiva. São Paulo: Cortez, 1984.

FRIGOTTO, G. Formação profissional no segundo grau: em busca do horizonte da "educação" politécnica. Rio de Janeiro: FIocruz; Politécnico de Saúde Joaquim Venâncio, 1988.

FRIGOTTO, G. Os circuitos da história e o balanço da educação no Brasil na primeira década do Século xx. Revista Brasileira de Educação, Campinas, v. 16, n. 46, p.235-273, jan./abr. 2011.

FRIGOTTO, G.; CIAVATTA, M. Educar o trabalhador cidadão produtivo ou o ser humano emancipado? Trabalho, Educação e Saúde, Rio de Janeiro, v. 1, n. 1, p. 45-60, mar. 2003.

FRIGOTTO, G.; CIAVATTA, M.; RAMOS, M. (Org.). Ensino médio integrado: concepção e contradições. São Paulo: Cortez, 2005a.

FRIGOTTO, G.; CIAVATTA, M.; RAMOS, M. A política de educação profissional no governo Lula: um percurso histórico controvertido. Educação E Sociedade, Campinas, v. 26 , n. 92 , p. $715-718$, out. 2005 b.

GAJARDO, M.; PURYEAR, J.M. (Ed.). Formas y reformas de la educación en América Latina. Santiago: LOM; PREAL, 2003.

KUENZER, A.Z. Ensino de segundo grau: o trabalho como princípio educativo. São Paulo: Cortez; Campinas: Autores Associados, 1988.

MACHADO, L. Politecnia, escola unitária e trabalho. São Paulo: Cortez; Campinas: Autores Associados, 1989.

MARINI, R.M. Dialética da dependência. Petrópolis: Vozes, 2000.

MARX, K. O processo de produção do capital. In: MARX, K. O capital. (Crítica da economia política). 6. ed. Rio de Janeiro: Civilização Brasileira, 1980. Livro 1. 
MARX, K. Prefácio. In: MARX, K. Contribuição à crítica da economia política. São Paulo: Martins Fontes, 1983

MARX, K.; ENGELS, F. A ideologia alemã (Teses ad Feuerbach). São Paulo: Ciências Humanas, 1979.

MÉSZÁROS, I. Para além do capital. São Paulo: Boitempo, 2002.

MÉSZÁROS, I. O desfio e o fardo do tempo histórico. São Paulo: Boitempo, 2007.

MORAES, C.S.V. Relatório do Simpósio sobre Ensino Médio e Educação Profissional. Apresentado no 3. Seminário de Educação Brasileira, Campinas, 2011.

NOSELLA, P. Trabalho e perspectiva de formação dos trabalhadores: para além da formação politécnica. Revista Brasileira de Educação, Campinas, v. 12, n. 34, p. 137-151, jan./abr. 2007.

OLIVEIRA, F. Entre a terra e o céu: mensurando a utopia? Democracia Viva, Rio de Janeiro, n. 6, ago. 1999.

OLIVEIRA, F. Crítica à razão dualista; O ornitorrinco. São Paulo: Boitempo, 2003a.

OLIVEIRA, F. Entrevista concedida a Fernando Haddad e Leda Paulani. Revista Reportagem, Brasília, DF, n. 41, fev. 2003b.

OLIVEIRA, F. Política numa era de indeterminação: opacidade e encantamento. In: Oliveira, F.; Rizek, S.S. A era da indeterminação. São Paulo: Boitempo, 2007. p. 15-45.

OLIVEIRA, J.A.M. et al. [Carta ao] Presidente da Câmara de Educação Básica do CNE, Francisco Aparecido Cordão. Brasília, DF: MEC/SETEC, 2011.

QUIJANO, A. Colonialidad del poder, poder, eurocentrismo y América Latina. In: LANDER, E. (Comp.). Colonialidad del saber, eurocentrismo y ciencias sociales. Buenos Aires: CLACSO; UNESCO, 2000. p. 201-246.

SCHULTZ, T. O capital humano. Rio de Janeiro: Zahar, 1973.

RODRIGUES, J. A educação politécnica no Brasil. Niterói: EDUfF, 1998.

RODRIGUES, J. Qual cidadania? Qual democracia? Qual educação? Trabalho, Educação e Saúde, Rio de Janeiro, v. 4, n. 2, p. 417-430, 2006.

RUMMERT, S.M. Educação de jovens e adultos no Brasil atual: do simulacro à emancipação. Perspectiva, Florianópolis, v. 26, n. 1, p. 175-208, jan./jun. 2008.

SAVIANI, D. Sobre a concepção de politecnia. Rio de Janeiro: FIOcruz, 1989. 
Perspectivas sociais e políticas da formação de nível médio...

SAVIANI, D. O choque teórico da politecnia. Trabalho, Educação E Saúde, Rio de Janeiro, n. 1, p. 131-52, 2003.

SAVIANI, D. O Plano de Desenvolvimento da Educação: análise do Projeto do MEc. Educação E Sociedade, Campinas, v. 28, n. 100, p. 1231-1255, out. 2007.

Recebido em 29 de junho de 2011.

Aprovado em 12 de agosto de 2011. 